\title{
Badania bezpieczeństwa jazdy po wichrowatym torze. Porównanie wymagań wg ORE, PN-EN i TSI.
}

\begin{abstract}
$W$ artykule, zaprezentowano sposoby oceny bezpieczeństwa jazdy po wichrowatym torze. Przybliżono metody badań jakie obowiqzuja wg PN-EN i ORE, ze szczególnym uwzględnieniem różnic występujacych pomiędzy dokumentami wtych metodach. Odniesiono się również do wymagań zawartych $w$ przepisach TSI dla wagonów towarowych, pojazdów konwencjonalnych i taboru dużych szybkości
\end{abstract}

\section{Wstęp}

Podczas eksploatacji pojazdów szynowych zauważono, że znaczna część wykolejeń następuje w czasie przejazdu przez łuki z przechyłką oraz rozjazdy. Do oceny zjawiska wprowadzono pojęcie bezpieczeństwa jazdy po wichrowatym (zwichrowanym) torze.

Jako miarę sytuacji wykolejenia spowodowaną wspinaniem się obrzeża koła na szynę przyjęto maksymalny iloraz siły poprzecznej do siły pionowej wg kryterium Nadala [1]

$$
(Y / Q)_{\lim }
$$

2. Podobieństwa i różnice $\mathbf{w}$ badaniu bezpieczeństwa jazdy po wichrowatym torze zawarte w normie PN-EN 14363 i ORE B55 RP 8

Norma PN-EN 14363 [1] obowiązuje dla wszystkich pojazdów szynowych. Uwzględnia ona również przypadki badania pojazdów wyposażonych w usprężynowanie pneumatyczne, jak i podaje metody badania pojazdów przegubowych ze wspólnym wózkiem umieszczonym pomiędzy członami. Odnosi się także do badania pojazdów wyposażonych w więcej niż dwa stopnie usprężynowania.

Raport ORE B55 RP8 [2] formalnie dotyczy tylko badania wagonów towarowych.

\subsection{Metody badań podane w normie i raporcie}

W normie PN-EN 14363 [1] podano 3 metody badań bezpieczeństwa jazdy po wichrowatym torze, tj.:

- metoda 1 - badanie na zwichrowanym torze,

- metoda 2 - badanie na specjalnym stanowisku do badania wichrowania i torze badawczym bez przechyłki,

- metoda 3 - badanie na specjalnym stanowisku do badania wichrowania i stanowisku do pomiaru skrętu.
W Raporcie ORE B55 RP 8 [2] podano 2 metody badań, tj.:

- metoda 1 - badanie na zwichrowanym torze,

- metoda 2 - badanie na specjalnym stanowisku do badania wichrowania i torze badawczym bez przechyłki.

Już na pierwszy rzut oka można zauważyć, że norma [1] dopuszcza więcej metod badania bezpieczeństwa jazdy po wichrowatym torze niż raport [2].

2.2. Podobieństwa i różnice badań pojazdów występujące w metodzie 1 - badanie na zwichrowanym torze badawczym

Zgodnie z metodą 1, opisaną w PN-EN 14363 [1], ocenę bezpieczeństwa jazdy przeciw wykolejeniu należy przeprowadzić dokonując pomiarów pionowej i poprzecznej siły podczas przejazdu przez zwichrowany tor.

\subsubsection{Tor badawczy}

Zgodnie z normą PN-EN 14363 [1] oraz raportem ORE B55 RP 8 [2] podczas przejazdu przez tor badawczy $\mathrm{z}$ wichrowatością należy przeprowadzić pomiary następujących wielkości:

- sił prowadzących na wewnętrznym i zewnętrznym kole badanego zestawu kołowego $\mathrm{Y}_{\mathrm{i}}$ i $\mathrm{Y}_{a}$;

- sił pionowego nacisku na wewnętrznym i zewnętrznym kole badanego zestawu kołowego $\mathrm{Q}_{\text {, }}$, $\mathrm{Q}_{\mathrm{a}}$,

- uniesienia koła prowadzącego $\Delta \mathrm{z}$ badanego zestawu w całym łuku.

Dodatkowo norma [1] zaleca wykonanie pomiarów kąta nabiegania zestawu prowadzącego $\alpha$, który jest niezbędny do określenia warunków tarcia (w trakcie badań współczynnik tarcia musi być co najmniej 80\% wartości oczekiwanej dla suchej szyny). Raport ORE B55 RP 8 [2] stawia również wymagania przeprowadzenia testów w warunkach o dużym współczynniku tarcia. Zaleca on przed przeprowa- 
dzeniem badań specjalnie przygotować tor, tzn. na początku przemyć go środkiem chemicznym (rozpuszczalnikiem), a następnie posypać piaskiem i go zmieść $\mathrm{z}$ toru.

Dokumenty [1] i [2] podają, że wichrowatość toru należy realizować poprzez zmianę wysokości położenia szyny zewnętrznej.

Parametry toru badawczego, wymienione $\mathrm{w}$ [1] i [2], są takie same tj.:

- promień łuku $\mathrm{R}=150[\mathrm{~m}]$,

- odcinek zwichrowanego toru ze stałym promieniem łuku i wichrowatością $g=3[\%]$.

Raport ORE [2] nie precyzuje lokalizacji miejsc pomiarowych, natomiast norma [1] zezwala, aby urządzenia rejestrujące siły kontaktu zostały umieszczone na szynie lub na pojeździe. Lokalizacja urządzeń do pomiaru sił, w przypadku gdy pomiar sił realizowany jest za pomocą urządzeń umieszczonych $\mathrm{w}$ torze, musi spełniać, zgodnie z normą [1], warunki przedstawiono na Rys. 1.

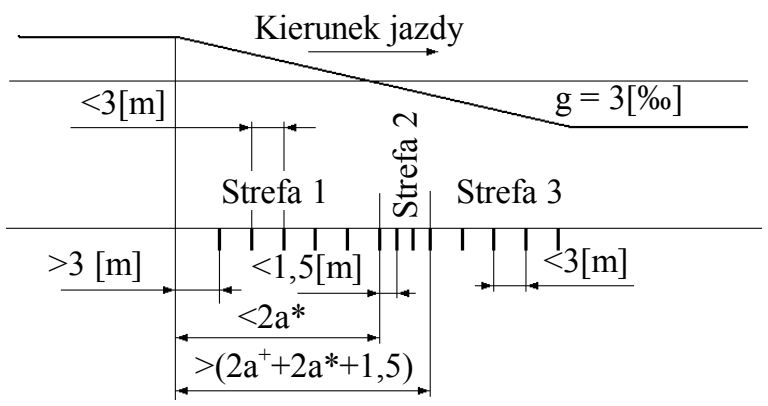

Rys. 1. Schemat rozmieszczenia punktów pomiarowych na torze badawczym z przechyłką

\subsubsection{Przygotowanie pojazdu do badań}

Zgodnie z normą PN-EN 14363 [1] oraz raportem ORE B55 RP 8 [2] badanie powinno być tak zaplanowane, aby koło prowadzące na zewnętrznej szynie łuku było kołem o najmniejszej sile pionowego nacisku.

Graniczne wichrowatości pojazdu o bazie 4,5 [m] ? $2 \mathrm{a}^{*}<20,0[\mathrm{~m}]$ podane $\mathrm{w}$ normie [1] i raporcie [2] są takie same, natomiast norma [1] dodatkowo podaje zależności dla pojazdów o większej bazie $2 \mathrm{a}^{*}$ ? 20 [m].

Jeżeli badana wichrowatość pojazdu jest większa niż 3 [\%o] to, zgodnie z [1] i [2], należy w odpowiedni sposób wprowadzić dodatkową wichrowatość $\mathrm{w}$ obrębie pojazdu. Dokonuje się tego poprzez dodatkowe pionowe uniesienie pojazdu np. przez umieszczenie podkładek pod sprężynami I-go i II-go stopnia usprężynowania. Raport [2] nie podaje metody wyliczenia podkładek i sposobu ich rozmieszczenia, natomiast w normie [1] podano wzory służące do wyznaczenia dodatkowego pionowego uniesienia i grubości podkładek. Na Rys. 2. przedstawiono schemat umieszczenia podkładek na pojeździe w celu zwiększenia jego wichrowatość.

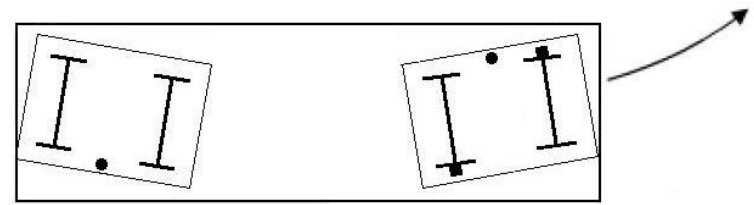

- Podkładki dla zwichrowania wózka

- Podkładki dla zwichrowania nadwozia

Rys. 2. Schemat usytuowania podkładek zwiększających wichrowatość $\mathrm{w}$ pojeździe

W przypadku, gdy koło prowadzące nie jest kołem o najmniejszej sile pionowego nacisku, należy umieścić podkładki pod sprężynami doprowadzając do sytuacji, gdzie koło prowadzące będzie wykazywało najmniejszą siłę pionowego nacisku.

Zgodnie z [1] i [2] prędkość przejazdu przez łuk powinna być stała i nie powinna przekraczać $\mathrm{V}<10$ $\mathrm{km} / \mathrm{h}$. W trakcie badań należy wykonać minimum 3 przejazdy, podczas których uniesienie koła zewnętrznego zestawu prowadzącego $\Delta \mathrm{z}$ powinno być rejestrowane w sposób ciagły.

Norma [1] precyzuje jak należy prowadzić rejestrację pomiarów, tzn. podaje, że dla każdej sekcji pomiarowej powinno się zarejestrować wartość $(\mathrm{Y} / \mathrm{Q})_{\mathrm{a}},(\mathrm{Y} / \mathrm{Q})_{\mathrm{i}} \mathrm{i} \alpha$ na zestawie prowadzącym.

\subsubsection{Wielkości oceniane}

Zgodnie z [1] i [2] pojazd jest uważany za bezpieczny jeżeli podczas przejazdu po wichrowatym torze, jest spełniony warunek (1) w każdym badaniu.

W przypadku gdy wartość $(Y / Q)_{\lim }>1,2$ można dokonać ponownego sprawdzenia zachowania się pojazdu poprzez sprawdzenie czy warunek (2) jest zachowany:

$$
\Delta z_{\max } \leq \Delta z_{\lim }=5[\mathrm{~mm}]
$$

Raport ORE B55 RP 8 [2] uważa pojazd za bezpieczny podczas przejazdu przez wichrowaty tor po spełnieniu (2). Natomiast zgodnie z normą PN-EN 14363 [1] dodatkowo pojazd musi spełniać następujące warunki:

- kąt obrzeża nie przekracza $70^{\circ} \mathrm{w}$ żadnym położeniu na profilu koła (profil koła powinien być zarejestrowany i dodany do sprawozdania $z$ badań),

- powinno być udokumentowane, że obrzeże zewnętrznej szyny jest suche i żadne pozostałości smaru nie są tam obecne.

2.3. Podobieństwa i różnice badań pojazdów występujące $\mathrm{w}$ metodzie 2 - badanie na stanowisku do wichrowania i torze badawczym bez wichrowatości.W tej metodzie obliczenie współczynnika $(Y / Q)_{\mathrm{a}}$ opiera się na pomiarze spadku siły pionowego nacisku koła $Q_{\mathrm{a}}$ na stanowisku badawczym posiadającym możliwość symulacji zwichrowanego toru oraz pomiarze siły prowadzącej $Y_{\text {a }}$ na odpowiednim torze badawczym. 


\subsubsection{Pomiary siły pionowego nacisku koła $Q$ na} stanowisku do wichrowania

Podczas badania na stanowisku do wichrowania należy przeprowadzić pomiary następujących wielkości:

- przemieszczenia $\Delta \mathrm{z}_{\mathrm{jk}}$ kół;

- $\quad$ siły pionowego nacisku $\mathrm{Q}_{\mathrm{jk}}$ kół.

Oba dokumenty tj. norma PN-EN 14363 [1] i raport ORE B55 RP 8 [2] podają graniczne wielkości wichrowania. Zależności wykorzystywane jako podstawa w tym badaniu są takie same jak w metodzie 1 . W rzeczywistości uniesienie koła do $5 \mathrm{~mm}$ jest dozwolone. W związku z tym efektywne wichrowatości pojazdu zostały zredukowane.

Graniczne wichrowatości pojazdu o bazie 4,5 [m] ? $2 \mathrm{a}^{*}<20,0[\mathrm{~m}]$ podane $\mathrm{w}$ normie [1] i raporcie [2] są takie same, natomiast norma [1] dodatkowo podaje zależności dla pojazdów o większej bazie $2 \mathrm{a}^{*}$ ? 20 [m].

Różnice pomiędzy PN-EN i ORE istnieją w sposobie przemieszczania zestawów kołowych podczas próby wichrowania. Raport [2] podaje dwie metody wichrowania tj. badanie na nieruchomym lub na ruchomym zestawie kołowym. W raporcie [2] podano które koło jest badane, a które koła są przemieszczane. Norma [1] przewiduje tylko jeden sposób przemieszczania kół $\mathrm{w}$ trakcie badania bezpieczeństwa jazdy po wichrowatym torze.

\subsubsection{Wyznaczenie sił prowadzących $\mathrm{Y}$}

Metody badania bezpieczeństwa jazdy po wichrowatym torze przedstawione w raporcie ORE B55 RP 8 [2] dotyczą badania wagonów towarowych, które są przeważnie wyposażone $\mathrm{w}$ zunifikowane układy biegowe (wózki). Dlatego też w raporcie [2] przewidziano możliwość analitycznego wyznaczenia sił prowadzących $Y$.

Norma PN-EN 14363 [1] nie przewiduje wyznaczenia sił prowadzących $Y$ za pomocą wzorów empirycznych, a jedynie na torze badawczym.

Przy wyznaczeniu sił prowadzących, zgodnie $\mathrm{z}$ normą [1] oraz raportem [2], należy przeprowadzić pomiary następujących wielkości:

- sił prowadzących na wewnętrznym i zewnętrznym kole badanego zestawu kołowego $Y_{\mathrm{i}}$ i $Y_{a}$;

- siły pionowego nacisku na wewnętrznym kole badanego zestawu kołowego $Q_{\mathrm{i}}$.

Dodatkowo norma [1] zaleca wykonanie pomiarów kąta nabiegania zestawu prowadzącego $\alpha$. Kąt ten jest niezbędny do określenia warunków tarcia.

Schemat rozmieszczenia punktów pomiarowych przedstawiono na Rys. 3.

\subsubsection{Wielkości oceniane}

Zgodnie z [1] i [2] pojazd jest uważany za bezpieczny jeżeli warunek (3) jest spełniony.

$$
(Y / Q)_{j a} \leq 1,2[\mathrm{~mm}]
$$

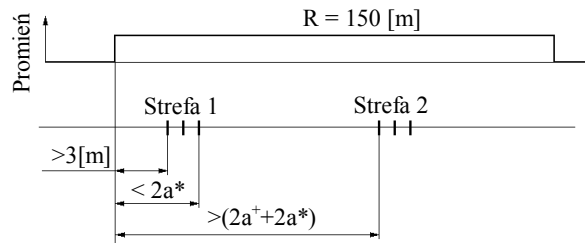

Rys. 3. Schemat rozmieszczenia punktów pomiarowych na torze badawczym bez przechyłki

Raport [2], w przypadku niespełnienia kryterium (3), zaleca przeprowadzenie ponownego badania zgodnie z metodą 1. Natomiast norma [1] traktuje metodę 1 i 2 jako równorzędne i nie przewiduje, w przypadku niespełnienia kryterium (3), ponownego badania inną metodą.

2.4. Metoda 3 wg PN-EN 14363 - Badanie na stanowisku do wichrowania i stanowisku do pomiaru momentu oborowego wózka względem nadwozia

Norma PN-EN 14363 [1] wprowadza dodatkową metodę badania bezpieczeństwa jazdy po wichrowatym torze.

\subsubsection{Ograniczenia w stosowaniu metody 3}

Metoda 3 łączy laboratoryjne badania odciążania koła oraz badania momentu oporowego wózka. Może być ona użyta do badania pojazdów o konwencjonalnej technologii pod następującymi warunkami:

- pojazd wyposażony w wózki dwuosiowe, dwa wózki na pojazd,

- kąt obrzeża kół pomiędzy $68^{\circ}$ a $70^{\circ}$.

\subsubsection{Wielkości mierzone podczas badań}

Podczas badania na stanowisku do wichrowania należy przeprowadzić pomiary następujących wielkości:

- przemieszczenie $\Delta \mathrm{z}_{\mathrm{jk}}$ kół;

- siły pionowego nacisku $\mathrm{Q}_{\mathrm{jk}}$ wszystkich kół.

Wymienione powyżej wielkości powinny być mierzone w sposób ciagły.

Podczas badania na stanowisku do pomiaru momentu oporowego wózka względem nadwozia należy przeprowadzić pomiary następujących wielkości:

- kąt skręcenia wózka względem pudła $\Delta \psi^{*}$,

- moment Mz potrzebny do obrotu wózka.

Wymienione powyżej wielkości powinny być mierzone w sposób ciagły i rejestrowane na wykresie $\mathrm{Mz}=\mathrm{f}\left(\Delta \psi^{*}\right)$.

\subsubsection{Stanowisko do wichrowania pojazdów}

Stanowisko do symulacji przejazdu pojazdów przez tor zwichrowany powinno umożliwiać przemieszczanie zestawów kołowych przynajmniej jednego wózka. W trakcie pomiarów należy w sposób ciagły rejestrować przemieszczanie kół oraz pionowe naciski poszczególnych kół. 


\subsubsection{Stanowisko do pomiaru momentu oporowego} wózka względem nadwozia pojazdu

Stanowisko badawcze powinno mieć możliwość określenia momentu obrotu wózka do maksymalnego kąta skręcenia wózka względem nadwozia. Prędkość stanowiska powinna być stała i wynosić $1[\%$ s $]$ przynajmniej dla $\pm 75 \%$ amplitudy kąta skręcenia.

\subsubsection{Przygotowanie pojazdu do badań}

Badaniom poddaje się pojazd $\mathrm{w}$ stanie normalnych warunków eksploatacyjnych, czyli z wyposażeniem zwykle używanym w eksploatacji.

W przypadku pojazdów posiadających usprężynowanie pneumatyczne badania należy wykonać $\mathrm{z}$ napompowanymi sprężynami i ze sprężynami z wypuszczonym powietrzem.

Ze względu na stan obciążenia zespoły trakcyjne, wagony pasażerskie i towarowe, na stanowisku do wichrowania, powinny być badane w stanie próżnym, natomiast na stanowisku do pomiaru momentu oporowego wózka względem nadwozia powinny być badane w stanie próżnym i ładownym.

\subsubsection{Warunki prowadzenia badań}

Badanie bezpieczeństwa jazdy po wichrowatym torze zgodnie $\mathrm{z}$ metodą 3 należy przeprowadzić na stanowisku do badania wichrowania i na stanowisku do pomiaru momentu oporowego wózka względem nadwozia.

Sposób przemieszczanie kół jest identyczny jak w metodzie 2 ale $\mathrm{z}$ innymi wartościami granicznymi wichrowatości.

Podczas badania na stanowisku do pomiaru momentu oporowego wózka względem nadwozia wózek należy ustawić tak, aby oś czopa skrętu (oś obrotu wózka w płaszczyźnie poziomej) pokrywała się z osią obrotu stanowiska pomiarowego. Należy obracać w obu kierunkach do wartości kąta skręcenia:

$$
\Delta \psi^{*}=\frac{a^{*}}{R_{\min }}+\frac{0,020}{2 a^{+}}
$$

gdzie:

$$
\begin{aligned}
& \mathrm{a}^{*} \quad-\text { połowa rozstawu czopów skrętu } \\
& \text { [m], } \\
& 2 \mathrm{a}^{+}-\text {rozstaw zestawów kołowych w } \\
& \text { wózku [m], } \\
& \mathrm{R}_{\min } \quad-\text { minimalny promień przez jaki po- }
\end{aligned}
$$

\subsubsection{Wielkości oceniane}

Analiza zachowania się na wichrowatym torze powinna być wykonana dla zestawu prowadzącego zastosowaniem współczynnika odciążenia (5) i współczynnika oporu obrotu wózka (6).

$$
\frac{\Delta Q}{Q_{0}}
$$

gdzie:

$\mathrm{Q}_{0}$ - średnia siła pionowego nacisku koła badanego zestawu na poziomym torze (wichrowatość $\mathrm{g}^{+}=0 \mathrm{i} \mathrm{g}^{*}=0$ ),

$\Delta \mathrm{Q}$ - odchyłka od $\mathrm{Q}_{0} \mathrm{w}$ warunkach maksymalnej wichrowatości.

Współczynnik oporu obrotu wózka X powinien być obliczony z zależności (6)

$$
X=\frac{M_{z, R \min }}{2 a^{+} \cdot 2 Q_{0}}
$$

gdzie:

$\mathrm{M}_{z, \mathrm{Rmin}}$ - moment skrętu [kNm] potrzebny do obrotu wózka względem nadwozia pojazdu, dla kąta obrotu wózka wyznaczonego z (7),

$2 \mathrm{a}^{+}-$baza wózka (rozstaw skrajnych zestawów w wózku) [m],

$2 \mathrm{Q}_{0}-$ siła pionowego nacisku zestawu $[\mathrm{kN}]$.

$$
\Delta \Psi_{\text {eval }}^{*}=\frac{a^{*}}{R_{\min }}
$$

Pojazd jest uważany za bezpieczny podczas przejazdu po wichrowatym torze, jeżeli są spełnione jednocześnie następujące warunki:

$$
\frac{\Delta Q}{Q_{0}} \leq 0,6
$$

$\mathrm{X} \leq 0,1$ dla pojazdów pasażerskich i lokomotyw,

dla wagonów towarowych powinien on być poniżej wartości granicznej pokazanej na Rys. 4.

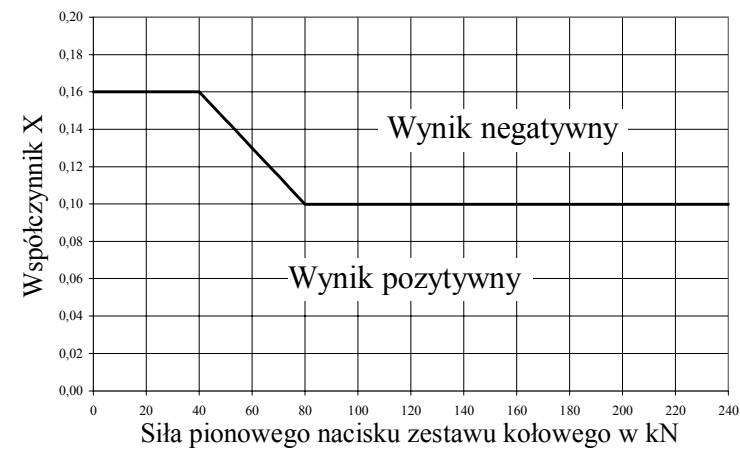

Rys. 4. Maksymalna dopuszczalna wartość współczynnika X dla wagonów towarowych

\section{Wymagania TSI}

Obecnie zatwierdzone przez Komisję Europejską są następujące dokumenty TSI:

- TSI WAG - decyzja nr 2006/861/WE [3] i decyzja nr 2009/107/WE [4],

- TSI HS - decyzja nr 2008/232/WE [5],

- TSI CR - w trakcie opracowania [6].

TSI nie podają metody badań - a jedynie kryteria oceny. 
W specyfikacjach TSI współczynnik $Y / Q$ rozpatrywany jest $\mathrm{w}$ dwóch aspektach: dynamicznym i quasistatycznym. W badaniu dynamicznym wartość graniczna współczynnika $Y / Q$ jest zgodna z (10), natomiast $\mathrm{w}$ badaniu quasistatycznym kryterium uzyskane jest $\mathrm{z}$ równania Nadal'a, czyli jest zgodne $\mathrm{z}$ (1).

$$
(Y / Q)_{\lim }=0,8
$$

\subsection{TSI WAG}

Wymagania zawarte w TSI WAG [3] i [4] nie podają metody badań bezpieczeństwa jazdy po wichrowatym torze. $\mathrm{W}$ punkcie rozdziale Zabezpieczenie przed wykolejeniem podczas jazdy po wichrowatych torach podane zostały tylko graniczne wichrowatości toru, które wagony powinny pokonywać bez przeszkód. Współczynnik $(Y / Q)$ podczas przejazdu przez tuk o promieniu $\mathrm{R}=150 \mathrm{~m}$, dla podanych wichrowatości, nie powinien przekraczać wartości granicznej. Graniczne wichrowatości są zgodne z normą PN-EN 14363 [1].

Poprawna wartość kryterialna współczynnika (Y/Q) została podana w decyzji nr 2009/107/WE [4]. Jest ona zgodna z kryterium Nadala - zależność (1).

\subsection{TSI HS}

TSI HS nie podaje granicznych wartości wichrowatości toru. W punkcie rozdziale Dynamiczne zachowanie sie taboru odwołuje się do procedur dopuszczenia pojazdów zgodnie z normą EN 14363 (polski odpowiednik to [1]) - podpunkty dotyczące badań dynamicznych zamieszczonych w [1]. Następnie $\mathrm{w}$ rozdziale Wartości graniczne dla bezpieczeństwa jazdy podane jest kryterium jako iloraz poprzecznej i pionowej siły wywieranej przez koło na torze zwichrowanym dla promienia łuku $\mathrm{R}<250 \mathrm{~m}$. Kryterium to jest zgodne z kryterium Nadala.

\subsection{TSI CR}

W projekcie TSI CR przewidywanym do wprowadzenia w 2010r. umieszczono rozdział Dynamiczne zachowanie się taboru. Jednak, w odróżnieniu do pozostałych TSI, w TSI CR znajduje się rozdział Badanie bezpieczeństwa jazdy po wichrowatym torze, który to całkowicie odwołuje się do wymagań normy EN 14363.

\section{Podsumowanie}

Celem referatu była prezentacja metod badań bezpieczeństwa jazdy po wichrowatym torze zawartych w normie PN-EN 14363 [1], raporcie ORE B55 RP 8 [2] oraz specyfikacjach technicznych TSI.

\section{Lit e r a t u r a}

[1] PN-EN 14363:2007 Kolejnictwo. Badania wtasności dynamicznych pojazdów szynowych przed dopuszczeniem do ruchu. Badania własności biegowych i próby stacjonarne.

[2] ORE B55 Rp 8 Prevention of derailment of goods wagon on distorted tracks. Conditions for negotiating track twists. Recommended values for track twist and cant. Calculation and measurement of the relevant vehicle parameters. Vehicle testing. Utrecht, April 1983.

[3] 2006/861/WE DECYZJA KOMISJI dotyczqca technicznej specyfikacji dla interoperacyjności odnoszqcej się do podsystemu ,tabor kolejowy - wagony towarowe" transeuropejskiego systemu kolei konwencjonalnych (notyfikowana jako dokument nr C(2006) 3345) z dnia 28 lipca $2006 r$.

[4] 2009/107/WE DECYZJA KOMISJI zmieniajaca decyzje 2006/861/WE i 2006/920/WE w sprawie technicznych specyfikacji interoperacyjności w zakresie podsystemów transeuropejskiego systemu kolei konwencjonalnych (notyfikowana jako dokument $n r$ C(2009) 38) z dnia 23 stycznia $2009 \mathrm{r}$.

[5] 2008/232/WE DECYZJA KOMISJI dotyczqca technicznej specyfikacji technicznej interoperacyjności podsystemu ",Tabor" transeuropejskiego systemu kolei dużych prędkości (notyfikowana jako dokument $n r$ C(2008) 648) z dnia 21 lutego $2008 \mathrm{r}$.

[6] Technical Specification for Interoperability transEuropean conventional rail system Subsystem rolling stock TSI "Locomotives and Passenger RST"- project końcowy z dnia 24.11.2009. 